Materials Science inc. Nanomaterials \& Polymers

\title{
Preparation and Comparison of Hydrolase-Coated Plastics
}

\author{
Eugenio Spadoni Andreani, ${ }^{[a]}$ Luca Magagnin, ${ }^{[b]}$ and Francesco Secundo ${ }^{*[a]}$
}

Polypropylene and polyethylene were coated with alpha-Chymotrypsin $(\alpha-\mathrm{CT})$ or subtilisin Carlsberg (SubC) or Burkholderia cepacia lipase (lipase BC) by different immobilization procedures, such as physical adsorption and covalent linking. This latter procedure was based on the chemical functionalization of the plastic surface by oxygen gas plasma treatment. Immobilization of the enzyme was carried out by using as cross-linking agent i) glutaraldehyde (GA) or ii) $\mathrm{N}^{\prime}$-diisopropylcarbodiimide (DIC) and N-hydroxysuccinimide (NHS). The effects of duration of the plasma treatment and the type of the immobilization procedure on the transesterification activity of the enzyme were investigated. In general polypropylene resulted a better support than polyethylene. Moreover, $\alpha-C T$ showed higher

\section{Introduction}

Enzyme immobilization is pursued to exploit the technological advantages offered by enzymes and to meet cost targets. ${ }^{[1-4]}$ In biocatalysis, the immobilized enzyme is easily separated from the reaction medium, allowing its repetitive use and simplifying the products separation steps. Immobilization can be a way to modify enzyme activity and selectivity ${ }^{[5]}$ and, especially if carried out establishing multipoint covalent attachment to the support, it can favor enzyme stabilization against deleterious harsh reaction conditions. ${ }^{[6-8]}$

A considerable number of methods and techniques for enzyme immobilization has been developed. Independently of the method, the kind of support and the binding of the enzyme to the surface can play a crucial role for the catalytic properties and performance of the immobilized enzyme ${ }^{[9]}$. On the other hand, factors such as reduced accessibility of the substrate to the catalytic active centre (e.g., unfavorable orientation of the enzyme molecule or substrate diffusional limitations), loss of the enzyme dynamic properties and/or alteration of the conformational integrity of the enzyme ${ }^{[10]}$ can be responsible for a low enzyme specific activity.

Concerning the support, an extremely high number of materials have been investigated for enzyme immobilization. In general, a support should possess desirable features such as

[a] E. Spadoni Andreani, Dr. F. Secundo

Istituto di Chimica del Riconoscimento Molecolare, Consiglio Nazionale delle Ricerche, via Mario Bianco 9, 20131, Milan, Italy

E-mail: francesco.secundo@icrm.cnr.it

[b] Ing. L. Magagnin

Dipartimento di Chimica, Materiali e Ing. Chimica G. Natta - Politecnico di Milano, via Mancinelli 7, 20131, Milano, Italy

Supporting information for this article is available on the WWW under http://dx.doi.org/10.1002/slct.201600377 transesterification activity when immobilized with GA, while for SubC, DIC and NHS were better cross-linking agents than GA. No activity was observed with these enzymes when immobilization was carried out by physical adsorption. On the contrary, lipase BC immobilized by physical adsorption was even more active than the free enzyme. Concerning thermal stability, immobilized SubC was less stable than the free enzyme. Overall, these results show that plastics endowed with biocatalytic properties could be obtained by simple immobilization protocols and that optimal immobilization conditions depend on the type of starting plastic, plasma treatment, cross-linking method, and the nature of the enzyme.

nano structuration that develops a higher surface/volume ratio, conductive properties (especially for amperometric biosensors), chemical and mechanical stability and low cost. Often the materials suggested as support are produced at the level of lab scale, and are far from being used in large scale applications. Instead, as a matter of fact, the choice of the supporting materials has to be taken on the basis of the final application of the biocatalyst. In this respect, the possibility to exploit largely employed and inexpensive materials (e.g., plastic polymers), appears very attracting for the use of immobilized enzymes in several commercial fields. Furthermore, the possibility to develop procedures that allow the linkage of enzymes on plastic surface might contribute to solve some problems commonly encountered by those objects made with these materials (e.g., biofilm formation on catheters or microbial growth on food packaging). However, plastic polymers such as polyethylene or polypropylene have several disadvantages that complicates protein immobilization. In particular, the inertness of plastic hinders the covalent binding of the enzyme to the support. To overcome this problem, gas plasma treatment is a strategy that has been adopted to modify polypropylene surface. ${ }^{[11]}$

The effects of the exposition of thin films of plastic materials to plasma has been investigated by several research groups. ${ }^{[12-14]}$ From these studies, it is possible to distinguish two main effects: i) the physical etching of the surface and ii) the introduction of radicals on the exposed polymer fibres, which then stabilize by forming functional groups with the ions found in the plasma and/or, after the exposition, in ambient air. Regarding thicker plastic layers, Howbrook et al. (2002 $)^{[15]}$ modulated the adsorption of DNA on a polypropylene (PP) plate by exposing it to radio frequency plasma treatment with $\mathrm{O}_{2}$ or with $\mathrm{N}_{2} / \mathrm{H}_{2}$ gas mixture. In particular, after the treatment with $\mathrm{O}_{2}$ plasma, DNA resulted less adsorbed on the plate, while with $\mathrm{N}_{2} / \mathrm{H}_{2}$ plasma the adsorption increased, thus it was suggested 
that these variations are due to the inclusion of negatively or positively charged functional groups on the PP surface, even though no analysis was performed to demonstrate this statement.

Using a similar plasma generator, N. Gomathi \& S. Neogi $(2009)^{[16]}$ treated $1.5 \mathrm{~mm}$ thick PP with $\mathrm{Ar} / \mathrm{O}_{2}$ plasma, and then characterized it via contact angle analysis, ATR/FT-IR and Atomic Force Microscopy (AFM). The study however did not find evidence such as of incorporation of oxygen-containing functional groups in the polymer.

In the present study, which was carried out in the context of our research on the development of materials with biocatalytic properties especially for biocatalysis in non-aqueous media, we investigated the covalent immobilization of proteases on $1.6 \mathrm{~mm}$ thick layer of PP or PE previously exposed to oxygen plasma. These plastic materials, because of their inertness and low cost, are widespread in many industrial and domestic applications (e.g., for packaging of food or for the construction of medical devices). The duration of the plasma treatment and the kind of the immobilization procedure were the main important factors herein studied, since they might strongly affect enzyme catalytic activity and stability.

\section{Results and Discussion}

\section{Oxygen plasma treatment of PP and PE coupons}

In order to favor the formation of chemical functionalities on the polymer surface, PP and PE coupons were exposed to plasma oxygen for different periods of time.

It is well known that plasma discharge leads to ablation of polymer surface layer and that the degree of modification and character of the surface changes generated depend on the composition of ambient atmosphere, energy of plasma ions, temperature during the treatment and discharge power. Using plasma oxygen treatment the incorporation of oxygen in the polymer surface might lead to the formation of hydroxyl, carbonyl, and/or carboxyl groups. ${ }^{[18,19]}$

The effect of plasma treatment evaluated via water contact angle over two days from the exposition are shown in Figure 1. The results show that the contact angle value decreases as a function of the duration of the exposition to plasma being $93.3 \pm 0.5^{\circ}$ for PP untreated coupons and $69.5 \pm 0.1,55.7 \pm 1.9$, $45.1 \pm 0.95^{\circ}$ after an oxygen plasma treatment of 10,20 and 30 min, respectively. A similar trend was observed for PE coupons and the contact angle varied from $99.3 \pm 0.8^{\circ}$ to $48.9 \pm$ $12.0,33.1 \pm 4.127 .0 \pm 3.9^{\circ}$ after 10,20 and $30 \mathrm{~min}$, respectively. The wider distribution on the surface of equal volume water droplets gives a lower contact angle value and is indicative of a more hydrophilic surface (higher wettability). Interestingly, the decrease of the contact angle observed after plasma treatment was reversible (hydrophobic recovery), and contact angles values reverted towards the initial values with a recovery rate inversely related to the variation between the value observed just after the plasma treatment and untreated surface. Hydrophobic recovery for plasma-treated plastic materials has previously been systematically investigated by Jokinen et al.
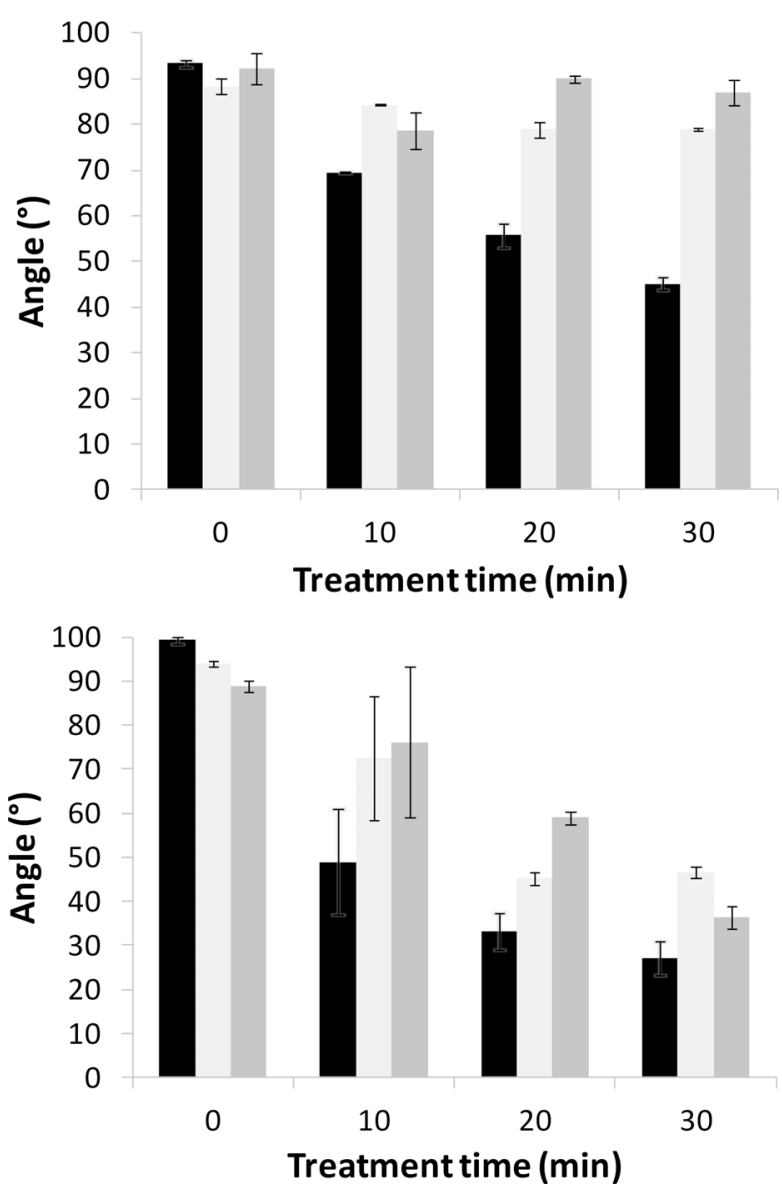

Figure 1. Contact angle as a function of time after the plasma treatment: just after treatment (black bars), after $24 \mathrm{~h}$ (light gray) and after $48 \mathrm{~h}$ (dark gray) for PP (above) and PE (below).

(2012). ${ }^{[20]}$ They observed this phenomenon even with a plasma power applied 10-fold higher than that employed in this study. It has been suggested that the principal reasons for the recovery might be the reorientation of the surface layer, or the migration of the polymer chains from the bulk of the polymer to the surface or vice versa. ${ }^{[21,22]}$ Nevertheless, plasma treatment on PE and PP shows some different effects. On PP it causes a lesser increase of wettability compared to that produced on $P E$, and the increase vanishes after 48 hours; instead, it is mostly preserved in PE (Figure 1). The higher instability of the plasma generated hydrophilicity also suggest a higher surface reactivity in PP, causing a faster reorientation of the surface layer. In addition, aging of the plasma treated plastic was carried out at room temperature and under atmospheric conditions, which might have favored adsorption of environmental nanoparticles, especially if in the presence of a higher number of reactive functional groups (e.g., with PP). Then, the higher surface reactivity would explain the higher retention of enzyme activity. But, it is crucial to carry out the enzyme immobilization reaction just after the plasma treatment.

AFM also provided indications of an effective modification of the PP surface upon plasma treatment. Table 1 and Figure 2 


\begin{tabular}{|lllll|}
\hline $\begin{array}{l}\text { Table 1. Average roughness (Ra), root mean square (RMS) roughness, aver- } \\
\text { age potential and RMS surface potential of untreated polypropylene sur- } \\
\text { face and after } 30 \text { min plasma treatment. }{ }^{[a]}\end{array}$ \\
$\begin{array}{l}\text { Plasma Treat- } \\
\text { ment (min) }\end{array}$ & $\begin{array}{l}\text { Ra } \\
(\mathrm{nm})\end{array}$ & $\begin{array}{l}\text { RMS } \\
\text { roughness } \\
(\mathrm{nm})\end{array}$ & $\begin{array}{l}\text { Average poten- } \\
\text { tial (mV) }\end{array}$ & $\begin{array}{l}\text { RMS po- } \\
\text { tential } \\
(\mathrm{mV})\end{array}$ \\
\hline 0 & $\begin{array}{l}5.4 \\
(18.6)\end{array}$ & $7.7(24.9)$ & $1.2(77.9)$ & $1.5(108.3)$ \\
30 & $\begin{array}{l}12.7 \\
(26.7)\end{array}$ & $17.7(35.4)$ & $28.9(252.9)$ & 42.0 \\
& & & $(358.6)$ \\
\hline [a] In parenthesis data for polyethylene \\
\hline
\end{tabular}

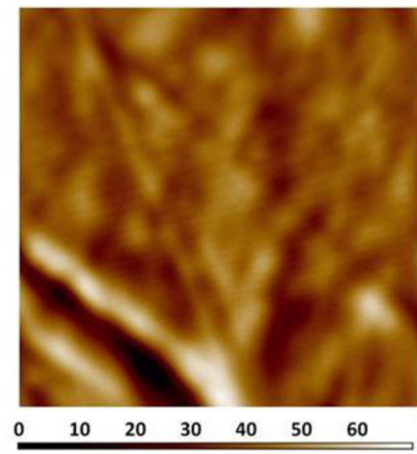

$\mathrm{nm}$

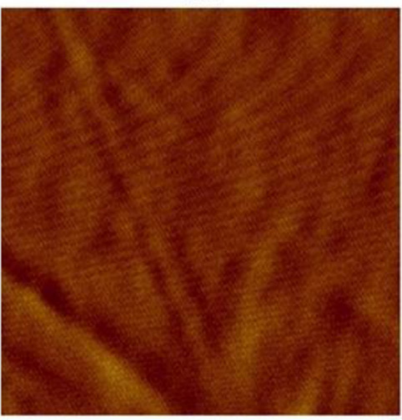

$-10$
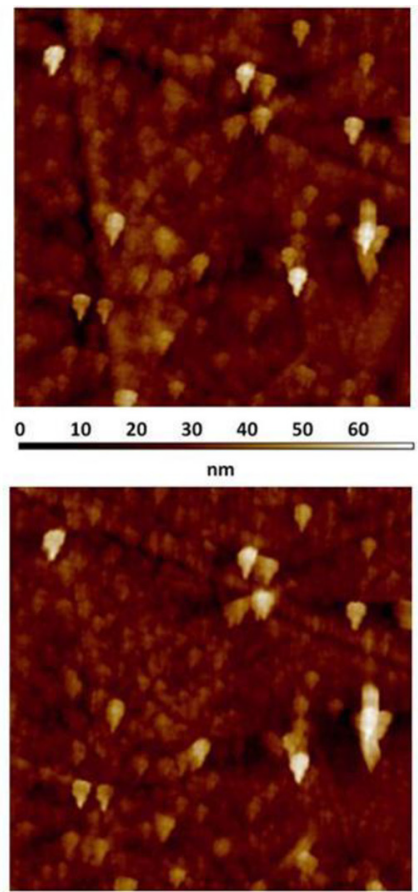

$\begin{array}{rrrrrrr}-100 & -50 & 0 & 50 & 100 & 150 & 200\end{array}$

Figure 2. AFM analyses of surface morphology (above) and potential (below) on polypropylene before (left column) and after $30 \mathrm{~min}$ of plasma treatment (right column). For Ra, RMS roughness, average and RMS surface potential values see Table 1. AFM analyses were carried out using a Solver Pro NT-MDT scanning probe microscope with Kelvin Probe for surface potential measurements. Scans of $20 \mu \mathrm{m} \times 20 \mu \mathrm{m}$ were acquired for each measurement in amplitude modulation tapping mode, using gold silicon tips.

compare morphology and surface potential of PP surfaces before and after $30 \mathrm{~min}$ of plasma treatment.

It can be noted a marked increase of the RMS roughness that passed from 7.7 to $17.7 \mathrm{~nm}$ (after $30 \mathrm{~min}$ of exposure). Furthermore, both the average potential and the RMS potential markedly increased after 30 min plasma treatment. The increase of Ra and RMS roughness corresponds to a higher real surface per unit of macroscopic geometrical area and that of average and RMS potential indicates the presence of higher number of chemical functionalities on the PP surface. An analogous trend was found for PE even though the differences in

roughness before and after plasma treatment were less pronounced than those observed for PP (Table 1, Figure 1S).

In order to shed light on the kind of polar groups formed on the polymer surface, FT/IR analysis was carried out. Because of the thickness of the PP or PE coupons employed in this study it was possible to monitor only some regions of the infrared spectra. In spite of this limitation, we could distinguish the insurgence of infrared signals in the region $1550-1750 \mathrm{~cm}^{-1}$ in the case of $P P$ and $P E$ and $3200-3600 \mathrm{~cm}^{-1}$ region only in the case of PP (Figure 3).
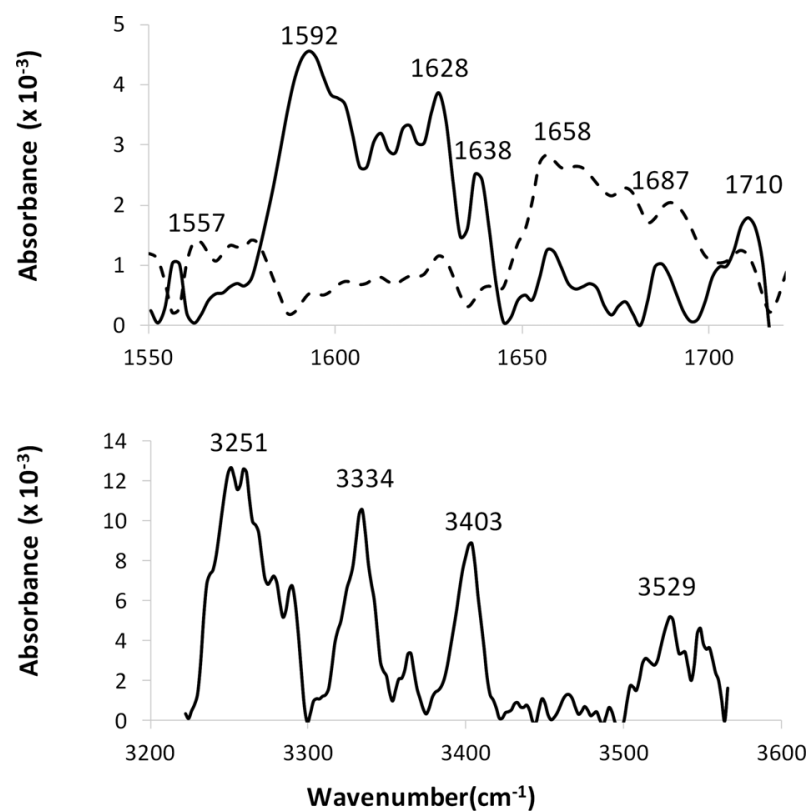

Figure 3. Infrared spectra of PP (continuous line) and PE (dashed line) coupons registered in the range of the $\mathrm{N}-\mathrm{H}$ and O-H stretching $(3200-3600 \mathrm{~cm}$ $1)$, and of the $\mathrm{C}=\mathrm{O}$ stretching $\left(1550-1750 \mathrm{~cm}^{-1}\right)$, just after plasma treatment carried out for $20 \mathrm{~min}$.

In the case of PP the most intense peaks at $1592 \mathrm{~cm}^{-1}$ suggest the presence of $\mathrm{C}-\mathrm{O}$ (e.g., due to the asymmetric stretching of carboxylate groups). On the other hand the peaks at $1628,1638,1658,1687,1710 \mathrm{~cm}^{-1}$, might be assigned to the $\mathrm{C}=$ O stretching of carboxyl or amide groups. In fact, we could not exclude the incorporation of nitrogen (e.g., to form amino or amide groups) in the polymer surface as also suggested by the presence of a peak at $1557 \mathrm{~cm}^{-1}$, which might be assigned to $\mathrm{N}-\mathrm{H}$ bending. Analogous assignment can be done for the peaks observed for the PE spectra in the $1550-1750 \mathrm{~cm}^{-1}$, even though the less intense peaks were observed in this case.

The incorporation of oxygen in the polymer is indicated also by the peaks observed at 3250, 3334, 3403 and $3529 \mathrm{~cm}^{-1}$ that can be assigned to $\mathrm{O}-\mathrm{H}$ groups. Analogously, also this signal might be partially due to the presence of $\mathrm{N}-\mathrm{H}$ groups on the surface of PP coupons, which also show a signal in this wavenumber range. Concerning the possibility to have amino groups on the polymer surface, it is worth pointing out that just after the plasma treatment, reactive species (e.g., radicals 
and peroxides) formed on the surface might evolve to double bonds or react with atmospheric nitrogen. ${ }^{[18]}$ Interestingly, Svorcik et al. (2006), ${ }^{[23]}$ after a Ar plasma treatment carried out for $400 \mathrm{~s}$ on high and low density polyethylene, observed by means of FT/IR the formation of peaks that were assigned to peroxide, ester, carbonyl, amide, carboxyl groups and to double bonds. In agreement with this research group, and in spite of the ambiguous peaks assignment, the insurgence of all these infrared signals indicates in both PE and PP the presence of functional groups exploitable for enzyme immobilization. Nevertheless, a different pattern of peaks in the infrared FT/IR spectra of plasma treated PE and PP might also support the hypothesis mentioned above of a higher reactivity of PP compared to $P E$. In particular, the peaks with maxima at 1592 and $1628 \mathrm{~cm}^{-1}$ (present only in plasma treated PP) can be assigned to hydroxyl and carboxyl groups, ${ }^{[24]}$ and show that the plasma treatment produces a different type of functional groups in PP compared to PE.

Hence, the analyses carried out for the surface characterization show that the oxygen plasma treatment was effective to prepare a plastic surface with higher specific surface area and surface reactivity, both features useful for increasing the yield of covalent enzyme immobilization.

Enzyme immobilization on polypropylene and polyethylene coupons.

Immobilization consists in the attachment of the enzyme to the support by interactions ranging from reversible physical adsorption and ionic linkages to stable covalent bonds. The formation of these latter ones usually leads to a lower leaching of the enzyme. Therefore, in order to prepare plastic materials coated with a stable enzyme layer we explored two different immobilization procedures (Scheme 1A, B) for covalent linkage.

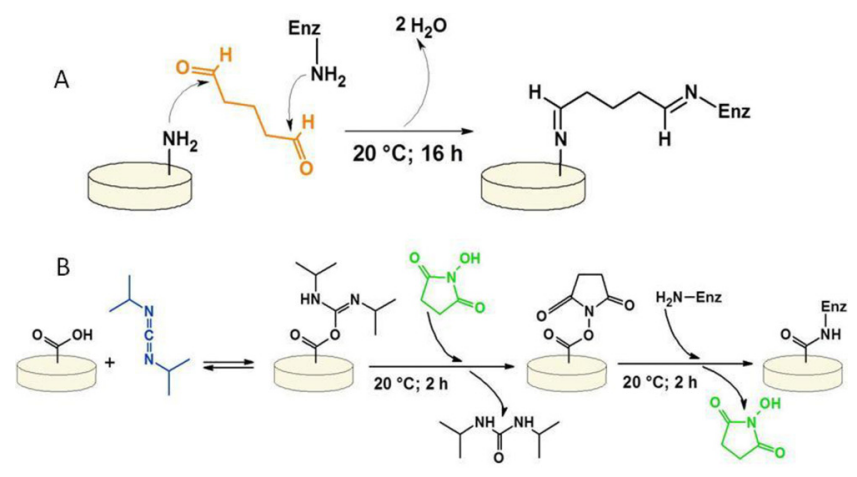

Scheme 1. Immobilization procedures adopted for enzyme covalent immobilization.

In the first protocol glutaraldehyde was selected as crosslinker. This bi-functional reagent can react with different enzyme moieties, mainly involving primary amino groups of proteins. Nevertheless, it is known that it can also react with other groups (thiols, phenols, and imidazole). ${ }^{[25]}$ In Scheme $1 \mathrm{~A}$ it is shown one of the mechanism by which the amino groups can react with glutaraldehyde, forming a Schiff base. However, it is important to emphasize that because it is not known what is the exact reactive structure of glutaraldehyde in the cross-linking reaction, there might be also other kinds of bonds formed between the support and glutaraldehyde and between this latter one with the protein. ${ }^{[26,27]}$

In a second immobilization protocol (Scheme 1B), surface plasma activation was followed by chemical modification by adding a succinimidyl moiety to the carboxyl groups expected to be present on the plastic surface. This step makes the modified carboxy groups readily reactive with the enzyme nucleophile groups (e.g., $\varepsilon$-amino groups of lysine). ${ }^{[28]}$

It is known that the duration of the plasma treatment might affect the chemical composition and degree of roughness of the surface. ${ }^{[23,24]}$ In particular the plasma treatment causes a higher surface to volume ratio and a higher number of functional groups (Table 1), thus possibly increasing the number of enzyme molecules that can accommodate on the plastic. In accordance with the data reported in the literature, ${ }^{[23,24]}$ we limited the plasma exposition to $30 \mathrm{~min}$. In fact, an excessive roughness of the surface could be a disadvantage for some applications of plastic (e.g., if used for catheters, high surface roughness could favor bacterial adhesion). The enzyme activity increased as a function of the duration of the plasma treatment of the polypropylene coupon, independently of the immobilization protocol adopted (Table 2). This result agrees with more

Table 2. Transesterification activity of $\alpha-C T$ and subtilisin immobilized on polypropylene or polyethylene ${ }^{[a]}$ coupons treated with oxygen plasma for different periods. ${ }^{[b], ~[c], ~[d], ~[e] ~}$

\begin{tabular}{|llll|} 
Enzyme and cross-linking agent & $10 \mathrm{~min}$ & $20 \mathrm{~min}$ & $30 \mathrm{~min}$ \\
\hline$\alpha$-CT-GA & $478(40)$ & 952 & 1230 \\
Subtilisin-GA & $101(7)$ & 110 & 152 \\
$\alpha$-CT-DIC + NHS & $345(21)$ & 392 & 581 \\
Subtilisin-DIC + NHS & $131(14)$ & 362 & 413 \\
\hline
\end{tabular}

[a] In parenthesis the enzyme activity of the enzyme immobilized on polyethylene. [b] Activity expressed as $\mu \mathrm{U}$ (see methods for definition of U). [c] The activity of $0.4 \mathrm{mg}$ of lyophilized enzyme (non immobilized) was $33 \mu \mathrm{U}$ and $444 \mu \mathrm{U}$ for SubC and $\alpha-\mathrm{CT}$, respectively. [d] No activity was observed when the enzyme was immobilized by physical adsorption on untreated or plasma treated PP or PE coupons. [e] Data standard deviation was $\leq 15 \%$.

functionalized surface which allows the linkage of an higher number of enzyme molecules.

The immobilization procedure also plays an important role on the final enzyme activity. Herein we observed that in the case of subC the covalent link with the succinimidyl moiety led to a more active immobilized enzyme compared to the immobilization with glutaraldehyde. On the contrary in the case of $\alpha-C T$, higher activity values were obtained when glutaraldehyde was used as cross-linker (Table 2), in agreement with our previous study where a beneficial effect of glutaraldehyde on the activity of $\alpha-C T$ in organic solvent was observed. ${ }^{[29]}$ Interestingly, the immobilized enzymes had a transesterification activity that was up to 3- and 13-fold higher than that of the free enzyme, for $\alpha-C T$ and SubC, respectively. To this end it has 
to be emphasized that the comparison of activity between the free and immobilized enzymes was carried using for the free enzyme the same amount of enzyme loaded onto the plastic coupon for immobilization. Therefore, the immobilization led to an increase of specific activity after enzyme immobilization. Because of such enhancement, it was not possible to determine the immobilization yield on the basis of activity data. Furthermore, although we found a low $(<5 \%)$ residual protease activity (assayed in aqueous buffer) in the washing water after immobilization, the low activity might be due the procedure adopted and not to the fact that the enzyme was bound to the plastic surface. The high enzyme concentration and the fact that the enzyme solution was left on the coupon over night to dry, might be responsible for autolysis and enzyme inactivation. Analogously, because of protein reaction with GA or $\mathrm{NHS}$, no reliable data were obtained by protein quantification (by OD at $280 \mathrm{~nm}$ or Biorad reagent).

The increase of specific activity for $\alpha-C T$ and SubC and other hydrolases in organic solvents, after immobilization or formulation, has been previously described. ${ }^{[30,31]}$ Apparently the increase observed in our study is not as high as those reported by other research groups for other formulations of these enzymes. In fact, Ru et al. (2001) observed 27000-fold increase of activity in hexane in the case SubC co-lyophilized with $\mathrm{KCl}^{[32]}$ and Van Unen et al, (1998) found up to 425 -fold enhancement of activity for $\alpha-C T$ in acetonitrile, when the enzyme was colyophilized with crown ethers. ${ }^{[3]}$ Nevertheless because of the difficulties to determine the amount of protein in our samples after enzyme immobilization, in our study the increase could have been underestimated.

Lipases are a group of enzymes extensively used in different industrial fields. In biocatalysis they have been employed in an extremely high number of synthetic reactions and kinetic resolution, in both buffer and non-aqueous media. In this study, the immobilization of lipase BC conducted by physical adsorption on $\mathrm{PE}$ and $\mathrm{PP}$ resulted in a more active enzyme compared to free enzyme and, even more so, to the enzyme covalently linked to the plastic. Instead, no significant effect of the immobilization was observed on lipase BC enantioselectivity (Table 3).

\begin{tabular}{|llll|}
\hline $\begin{array}{l}\text { Table 3. Transesterification activity and enantiomeric ratio (E) of lipase BC } \\
\text { immobilized by adsorption or covalent link to polypropylene or poly- } \\
\text { ethylene coupons. }{ }^{\text {[a], [b], [c] ], [d] }}\end{array}$ \\
Support & Adsorbed $^{[\mathrm{e}]}$ & $\mathrm{GA}^{[\mathrm{f}]}$ & $\mathrm{DIC}+\mathrm{NHS}^{[\mathrm{f}]}$ \\
\hline PE & $961(24)$ & $36(17)$ & $147(23)$ \\
PP & $1073(24)$ & $717(23)$ & $474(22)$
\end{tabular}

[a] Activity expressed as $\mu \mathrm{U}$. [b] With $0.4 \mathrm{mg}$ of lyophilized lipase (non immobilized) the activity was $517 \mu \mathrm{U}$ and $\mathrm{E}$ was 22 . [c] $\mathrm{E}$ value is in parenthesis. [d] Data standard deviation was $\leq 15 \%$. [e] The enzyme solution was loaded on non plasma treated plastic coupons in the absence of cross-linking reagents (see Enzyme immobilization in Methods for details). [f] Polypropylene or polyethylene was treated with oxygen plasma for $20 \mathrm{~min}$.
These results emphasizes the fact that the use of plastic supports as carriers for enzymes might be beneficial for the enzyme activity, especially for lipases that might be activated in the presence of an oil/water interface. In fact, the hydrophobic surface of PE or PP, simulating the oil surface, might favor the movement of the $\alpha$-helix domain (lid), that is present at the entrance of the catalytic site of lipase BC, towards the so called "open conformation" (e.g., a conformation that favors the access of the substrate to the catalytic active site), eventually leading to an increase of the enzyme activity. ${ }^{[34,35]}$ These results agree with those found by another research group that observed an increase of the catalytic activity of lipase from Pseudomonas cepacia (the former name of lipase BC) in the hydrolysis of $p$-nitrophenyl palmitate in organic solvent when the enzyme was immobilized on polypropylene. ${ }^{[36]}$

To evaluate the reusability of the enzymes, the recovered coupons were employed for a second reaction cycle. For all enzymes, the residual activity was only around $20 \%$ of that observed in the first cycle.

\section{Thermal stability}

Enzyme stability is a crucial parameter for the biotechnological applications of a given enzyme. In this study we evaluated the influence of immobilization on the thermal stability of SubC in water. The use of this reaction medium was preferred because the increased thermal stability of proteins in neat organic solvents $^{[37]}$ could make too lengthy and poorly reliable the experiments in these solvents.

Unfortunately, we found that immobilization was deleterious for SubC thermal stability, being the free enzyme more stable than the immobilized ones (Figure 4).

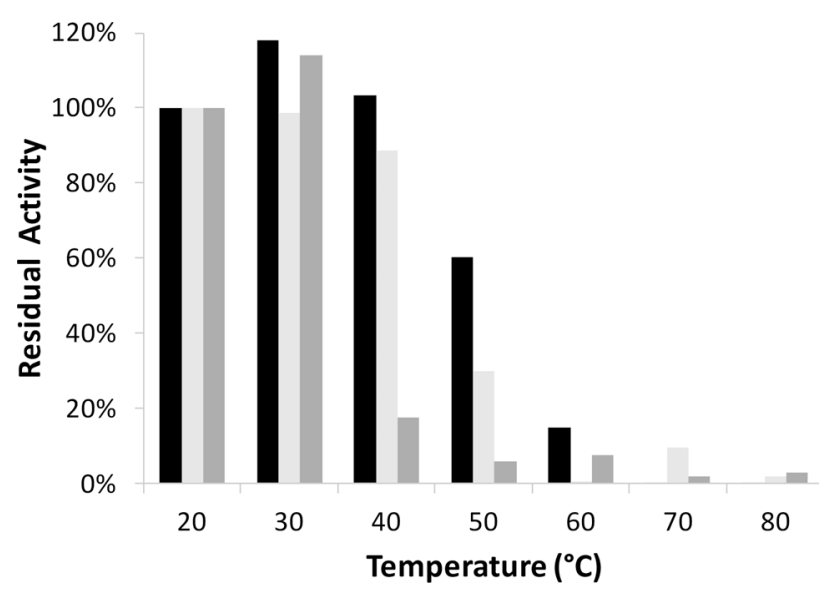

Figure 4. Residual activity of free (black bars) and immobilized subtilisin SubC-GA (light grey) or SubC-DIC (dark grey) as a function of temperature in buffer $\mathrm{A}$. The activity at $20^{\circ} \mathrm{C}$ was taken as $100 \%$. Measurements were carried out in triplicate and standard deviation was $\leq 15 \%$. For details see the Methods section.

The stability of the immobilized enzyme depended on the immobilization procedure. In particular, for SubC-DIC the re- 
sidual activity at $40^{\circ} \mathrm{C}$ was about $20 \%$ of the activity measured at $20^{\circ} \mathrm{C}$. Instead, SubC-GA followed more closely the profile of the free enzyme, even though, at $50{ }^{\circ} \mathrm{C}$, immobilization halved enzyme stability (residual activities were about $60 \%$ and $30 \%$ for the free enzyme and for SubC-GA, respectively). Interestingly, both immobilized enzymes retained a detectable activity after incubation at up to $80^{\circ} \mathrm{C}$, which was not the case for the free enzyme.

Dry disks with immobilized SubC withstand the whole array of tested temperatures (up to $80^{\circ} \mathrm{C}$ ) without significant loss of activity (Figure $2 \mathrm{~S}$ ).

\section{Conclusions}

The results herein presented show that PE and PP, which are the materials employed for the construction of a variety of industrial and domestic objects, biomedical devices and food packaging, can be functionalized by plasma treatment and coated with enzymes. Such a possibility appears promising not only for biocatalytic applications that require the use of immobilized enzymes, but especially for the development of inexpensive polymeric materials with added value (e.g. possessing biocatalytic properties). Although for lipase BC (and likely for other lipases endowed of an hydrophobic domain) a stable immobilization was obtained by simple adsorption on untreated plastic surface, for SubC and $\alpha-C T$ plasma treatment followed by a covalent linkage was crucial for the formation of a catalytically active coating on the plastic surface. In fact, no activity was found for these proteases when adsorbed on the plastic coupons.

Immobilization did not improve enzyme stability and, consequently, enzyme recycling was not effective. However, this drawback does not prevent the application of the strategy for the preparation of enzyme-coated plastics for single-use devices.

Furthermore, optimization of the plasma treatment with different plasma-gas (e.g., nitrogen or $\mathrm{Ar} / \mathrm{H}_{2}$ mixtures) and of the immobilization protocol might lead to more active and stable enzymes and enzyme preparations based on the use of easily available and inexpensive materials such as PE and PP.

\section{Supporting Information}

Detailed experimental section, Figures of AFM analyses on polyethylene and of Residual Activity of immobilized subtilisin after incubation at increasing temperatures.

\section{Acknowledgements}

We thank Fondazione Cariplo for financial support (Grant no. 2011-0277) and the Italian Ministry of Foreign Affairs, General Directorate for Cultural Promotion and Collaboration, which supported this work within the frame of the Executive Programme of Scientific and Technological Cooperation between the Italian Republic and the Republic of Poland for the years 2013-2015 (Prot. nr. 0086269, 17/04/2013; Prot. nr. 90692, 17/ 04/2014, Prot. nr. 75740, 10/04/2015).
Keywords: Enzyme coating $\cdot$ immobilization $\cdot$ plastic $\cdot$ plasma gas $\cdot$ biocatalysis

[1] U. Hanefeld, L. Gardossi, E. Magner, Chem. Soc. Rev. 2009, 38, 453-468.

[2] D. Brady, J. Jordaan, Biotechnology Letters. 2009, 31, 1639-1650.

[3] J. N. Talbert, J. M. Goddard, Colloids Surf. B, 2012, 93, 8-19.

[4] D. N. Tran, K. J. Balkus, ACS Catal. 2011, 1, 956-968.

[5] R. C. Rodrigues, C. Ortiz, Á. Berenguer-Murcia, R. Torres, R. FernándezLafuente, Chem. Soc. Rev. 2013, 42, 6290-6307; K. Breddam, M. Meldal. FEBS J. 1992, 206, 103-107.

[6] R. C. Rodrigues, Á. Berenguer-Murcia, R. Fernandez-Lafuente, Adv Synth. Catal. 2011, 353, 2216-2238.

[7] V. Grazú, O. Abian, C. Mateo, F. Batista-Viera, R. Fernández-Lafuente, J. M. Guisán, Biotechnol. Bioeng. 2005, 90, 597-605.

[8] O. Barbosa, C. Ortiz, Á. Berenguer-Murcia, R. Torres, R. C. Rodrigues, R. Fernandez-Lafuente, Biotechnol. Adv. 2015, 33, 435-456.

[9] J. C. S. dos Santos, O. Barbosa, C. Ortiz, A. Berenguer-Murcia, R. C. Rodrigues, R. Fernandez-Lafuente, ChemCatChem 2015, 7, 2413-2432.

[10] F. Secundo, Chem. Soc. Rev. 2013, 42, 6250-6261.

[11] T. Vorhaben, D. Böttcher, D. Jasinski, U. Menyes, V. Brüser, K. Schröder, U. T. Bornscheuer, ChemCatChem 2010, 2, 992-996.

[12] L. Kravets, A. Gilman, M. Yablokov, V. Elinson, B. Mitu, G. Dinescu, Plasma Process. Polym. 2013, 10, 603-618.

[13] E. Chichti, G. Henrion, F. Cleymand, M. Jamshidian, M. Linder, E. ArabTehrany, Plasma Process. Polym. 2013, 10, 535-543. D.

[14] S. Bhowmik, P. Jana, T. K. Chaki, S. Ray, Surf. Coat. Tech. 2004, 185, 81-91.

[15] D. Howbrook, D. Sarker, A. Lloyd, A. Louwrier, Biotechnol. Lett. 2002, 24, 2071-2074.

[16] N. Gomathi, S. Neogi, J. Adhes. Sci. Technol. 2009, 23, 1811-1826.

[17] C.-S. Chen, Y. Fujimoto, G. Girdaukas, C.J. Sih, J. Am. Chem. Soc. 1982, $104,25,7294-7299$.

[18] I. Junkar, A. Vesel, U. Cvelbar, M. Mozetič, S. Strnad, Vacuum 2009, 84, 83-85.

[19] K. Wulf, M. Teske, M. Löbler, F. Luderer, K.-P. Schmitz, K. Sternberg, J. Biomed. Mater. Res. B 2011, 98, 89-100.

[20] V. Jokinen, P. Suvanto, S. Franssila, Biomicrofluidics 2012, 6, 1-10.

[21] M. Morra, E. Occhiello, R. Marola, F. Garbassi, P. Humphrey, D. Johnson, J. Colloid Interf. Sci. 1990, 137, 11-24.

[22] C. C. Dupont-Gillain, Y. Adriaensen, S. Derclaye, P. G. Rouxhet, Langmuir. 2000, 16, 8194-8200.

[23] V. Švorčík, K. Kolářová, P. Slepička, A. Macková, M. Novotná, V. Hnatowicz, Polym. Degrad. Stabil. 2006, 91, 1219-1225.

[24] M.R. Sanchis, V. Blanes, M. Blanes, D. Garcia, R. Balart, Eur. Polym. J. 2006, 42, 1558-1568.

[25] A. F. S. A. Habeeb, R. Hiramoto, Arch. Biochem. Biophys.1968, 126,16-26.

[26] O. Barbosa, C. Ortiz, Á. Berenguer-Murcia, R. Torres, R. C. Rodrigues, R. Fernandez-Lafuente, RSC Adv. 2014, 4, 1583-1600.

[27] I. Migneault, C. Dartiguenave, M. J. Bertrand, K. C. Waldron, BioTechniques 2004, 37, 790-802.

[28] A. Guiseppi-Elie, A. M. Wilson, J. M. Tour, T. W. Brockmann, P. Zhang, D. L. Allara, Langmuir. 1995, 11, 1768-1776.

[29] F. Secundo, G. L. Barletta, G. Parini, G. Roda, J. Mol. Catal. B Enzym. 2012, 84, 128-131.

[30] F. Secundo, G. Carrea, Chem. Eur. J. 2003, 9, 3194-3199.

[31] M. N. Gupta, I. Roy, Eur. J. Biochem. 2004, 271, 2575-2583.

[32] M. T. Ru, K.C. Wu, J. P. Lindsay, J. S. Dordick, J. A. Reimer, D. S. Clark, Biotechnol. Bioeng. 2001, 75 , 187-196

[33] D. J. van Unen, J. F. J. Engbersen, D. N. Reinhoudt, Biotechnol. Bioeng. 1998, 59, 553-556.

[34] K. K. Kim, H. K. Song, D. H. Shin, K. Y. Hwang, S. W. Suh, Structure 1997, 5, 173-185.

[35] I. Mingarro, H. Gonzales-Navarro, L. Braco, Biochemistry 1996, 35, 9935-9944.

[36] G. Pencreac'h, J. C. Baratti, Appl. Microbiol. Biot. 1997, 47, 630-35.

[37] A. Zaks, A. M. Klibanov, J. Biol. Chem. 1988, 263, 3194-3201.

[38] K. Breddam, M. Meldal, Eur. J. Biochem. 1992, 206,103-107.

Submitted: April 12, 2016

Accepted: May 9, 2016 